\title{
A relação mãe-bebê com deficiência auditiva no processo de diagnóstico
}

The relationship of mother-baby hearing-impaired in the diagnosis process

La relación entre la madre y el bebé con pérdida auditiva en el proceso de diagnóstico

\author{
Midori Otake Yamada* \\ Cibelle Nunes Moretti** \\ Mariani da Costa Ribas do Prado ${ }^{* * *}$ \\ Maria Cecilia Bevilacqua (in memoriam) ${ }^{* * *}$
}

\begin{abstract}
Resumo
O objetivo deste estudo foi compreender a vivência de mães diante do processo de diagnóstico da deficiência auditiva do bebê. Participaram desta pesquisa sete mães de bebês diagnosticados com perda auditiva profunda, no Centro de Pesquisas Audiológicas do HRAC-USP. De acordo com a abordagem qualitativa, a análise dos resultados baseou-se no método fenomenológico. $\mathrm{O}$ estudo revelou que o diagnóstico da deficiência auditiva em um filho interfere negativamente na trajetória de vida das mães participantes. Entretanto, após a intervenção da equipe, elas puderam encarar a situação por uma nova perspectiva, a partir da elaboração do diagnóstico. Como a presença de sentimentos negativos nas mães constitui potencial fator de risco na relação mãe-bebê, identificar os fatores dessa relação que interferem de modo negativo no desenvolvimento da criança ajuda essa mãe no processo de aceitação do diagnóstico e, consequentemente, no estabelecimento de uma relação saudável com o seu filho.
\end{abstract}

Palavras-chave: Relações mãe-filho. Diagnóstico. Deficiência auditiva.

\footnotetext{
Abstract

This study is aimed at understanding the everyday life of mothers after learning about their children's hearing impairment diagnoses. Seven mothers whose babies were diagnosed with profound hearing loss at the Audiological Research Center with the HRAC-USP, participated in this research. Based on qualitative approach, the analysis of the results adopted

Texto recebido em junho de 2011 e aprovado para publicação em fevereiro de 2014.

* Doutora em Psicologia pela FFCLRB-USP. Endereço: Rua Silvio Marchione, 3-20 - Vila Universitária, Bauru-SP. CEP: 17012-900. Telefone: (14) 3235-8000, ramal 358587. E-mail: miotake@usp.br.

** Especialista em Psicologia, Hospital de Reabilitação de Anomalias Craniofaciais, Universidade de São Paulo (HRAC/USP), Bauru-SP. Endereço: Rua Prudente de Moraes, 880 - Jardim Arantes, Presidente Venceslau-SP. CEP: 19400-000. Telefone: (18) 3271-3386, fax: (14) 3234-7818. E-mail: cib_psico@yahoo.com.br.

${ }^{* * *}$ Mestra em Psicologia do Desenvolvimento e Aprendizagem (UNESP), Bauru-SP. Endereço: Rua Silvio Marchione, 3-20 Vila Universitária, Bauru-SP. CEP: 17012-900.

**** Doutora em Psicologia da Educação (PUC-SP), livre-docente (USP).
} 
the phenomenological method. The study showed that children's hearing impairment diagnoses negatively interfered with the life-path of mothers participating, however, following the intervention of the team, they were able to face the situation with a new perspective, from the elaboration of the diagnosis. Negative feelings within mother-baby relation could pose a potential risk factor, thus, identifying the factors of this relation which negatively interfere with the child's development may help the mother in the acceptance of the diagnosis process, and, consequently, in the establishment of a healthy relationship with her child.

Keywords: Mother-child relations. Diagnosis. Hearing impairment.

\section{Resumen}

El objetivo de este estudio fue comprender las vivencias de madres ante el proceso de diagnóstico de deficiencia auditiva del bebé. Participaron de esta pesquisa siete mamás de bebés diagnosticados con pérdida auditiva profunda, en el Centro de Pesquisas Audiológicas del HRAC-USP. El análisis de resultados se basó en el método fenomenológico. El estudio reveló que el proceso diagnóstico de deficiencia auditiva en un niño interfiere negativamente en la trayectoria de vida de las madres participantes. Sin embargo, después de la intervención, fueron capaces de ver la situación desde una nueva perspectiva, a partir de la compresión del diagnóstico. Como la presencia de sentimientos negativos en las madres es un factor de riesgo potencial de la relación madre-hijo, identificar los factores de la relación, que interfieren negativamente en el desarrollo del niño, pueden ayudar los padres en el proceso de diagnóstico de la aceptación y, por tanto, el establecimiento de una relación saludable con su hijo.

Palabras clave: Relaciones madre-hijo. Diagnóstico. Pérdida auditiva.

\section{Introdução}

S estágios iniciais do desenvolvimento humano são considerados por Winnicott essenciais, pois neles são constituídas as bases da personalidade e da saúde psíquica da criança. A principal relação, nos primeiros anos de vida de um bebê, é com a mãe. Para o desenvolvimento psíquico saudável, é necessário que a mãe se encontre no estado de "preocupação materna primária" (Winnicott, 2006), ou seja, em sintonia com o seu bebê. A maneira como a mãe toca o seu bebê, seja pelas mãos ou pelo olhar, a forma como ele é banhado, embalado, alimentado e o modo como ela lhe dirige a palavra permitem que o bebê entre em contato com as diversas partes do seu corpo e vivencie um sentimento de continuidade do ser. 
É na experiência com a mãe que o desenvolvimento da psique se inicia. A mãe fornece um setting no qual a constituição do bebê se mostra, suas tendências de desenvolvimento começam a se revelar, e o bebê experimenta um movimento espontâneo e domina as sensaçóes apropriadas a essa fase inicial da vida, ou seja, nessa fase, há uma grande ênfase no vínculo entre o recém-nascido e a mãe. Quase tudo depende da relação da mãe com o bebê, se ela age como mãe suficientemente boa, auxiliando-o em seu desenvolvimento (Winnicott, 2006).

Nesta pesquisa, o interesse especial é desvelar a relação mãe-bebê com deficiência auditiva, no processo de diagnóstico. $\mathrm{O}$ foco de atenção reside em compreender como as mães que se encontram nesse processo vivenciam a sua relação com o bebê.

No cotidiano profissional, percebe-se que o diagnóstico da deficiência auditiva tem ocorrido cada vez mais cedo na vida da criança, seja por meio dos programas de triagem auditiva neonatal (TAN), cujo objetivo é identificar os neonatos com suspeita de deficiência auditiva, seja por meio dos encaminhamentos realizados pelos profissionais da saúde aos centros especializados. Mahl, Mattiazzi, Angst, Kessler e Biaggio (2013) ressaltam as reações negativas das mães que não sabem o que é a TAN, no momento da realização desta e enfatizam a importância de conscientizar essas mães sobre a importância de tal triagem para o diagnóstico precoce da deficiência auditiva.

É inegável a importância do diagnóstico e da intervenção precoce na deficiência auditiva da criança, especialmente no que se refere aos benefícios no desenvolvimento da fala e da linguagem (Mahl et al., 2013). Para Moret (2005), Costa, Bevilacqua e Nascimento (2006) e Pontes (2005), as consequências da deficiência auditiva são amplas e devastadoras, principalmente quando é de grau severo ou profundo. Nos primeiros anos de vida, além de impedir ou prejudicar a aquisição da linguagem oral, a deficiência auditiva acarreta dificuldades no convívio familiar e social, comprometendo o desenvolvimento global e a sua qualidade de vida. Conforme destaca Redondo e Carvalho (2000), pode ainda interferir no desempenho acadêmico e, na fase adulta, causar dificuldades quanto à profissionalização.

De acordo com Yamada (2006), Solé (2006) e Yamada e Valle (2013), o nascimento de uma criança com deficiência auditiva é um momento traumático e desestruturador para a família, alterando o seu equilíbrio anterior e determinando o aparecimento de um conjunto de problemas específicos, o que pode gerar um estado de tensão nas interações entre criança e cuidador e provocar estresse parental. Após a confirmação do diagnóstico de deficiência auditiva, os pais manifestam sentimentos como desilusão, fracasso e culpa e, muitas vezes, perdem 
a noção de que a criança tem muitas outras potencialidades além de ouvir e falar (Guimarães, 2005; Silva \& Gonçalves, 2013).

Os exames auditivos em recém-nascidos tornaram-se uma prática rotineira, sendo necessário compreender o seu impacto na ansiedade e vulnerabilidade da família. Essa compreensão é importante para instruí-la, pois a ansiedade tem um efeito adverso no relacionamento pais-bebê, constituindo, portanto, um dos fatores de risco relacionados aos exames auditivos e ao resultado (Stuart, Moretz $\&$ Yang, 2000). Nesse sentido, Yoshinaga-Itano e Deuzcategui (2001) afirmam que a "falha" no teste de triagem auditiva pode ocasionar nos pais um estado de choque, raiva, confusão, medo, depressão, solidão e vergonha. Kurtzer-White e Luterman (2003) ressaltam que, antes da TAN, os pais tinham tempo para observação de seus filhos e desenvolvimento das próprias suspeitas a respeito de um possível diagnóstico de deficiência auditiva, porém, com a TAN, a notícia da possibilidade do filho ter deficiência auditiva ocorre em um momento vulnerável da vida da família, no qual os pais estão estabelecendo seu novo papel na estrutura familiar que está se formando com a chegada de um novo membro.

Considerando que a relação mãe-filho é a base de toda a estruturação psíquica e constituição linguística infantil, a fala excessiva da mãe ou a sua ausência no diálogo com seu filho pode ser obstáculo ao funcionamento da linguagem infantil, uma vez que não proporciona o ambiente necessário para que a criança desenvolva a fala (Beltrami, Souza \& Dias, 2013). Com o impacto do diagnóstico, pode ocorrer uma ruptura na relação mãe-filho, afetando o processo de aquisição de linguagem, já que esta é adquirida naturalmente nessa relação, por meio de sinais espontâneos, expressões faciais, corporais e orais. Tudo se torna diferente: o modo de cuidar, de conversar e de responder aos estímulos da criança. $\mathrm{O}$ vínculo mãe-bebê pode ser prejudicado e originar um distanciamento entre a díade mãe/ bebê, predominando na mãe sentimentos negativos de tristeza, angústia, culpa e frustração diante da situação (Yamada, 2006; Yamada \& Valle, 2013).

O impacto da presença de uma deficiência na criança tende a ser maior quanto maiores forem as expectativas da mãe sobre o nascimento do filho. Para Winnicott, qualquer interferência nos processos naturais de relacionamento entre a mãe e o bebê pode desencadear distúrbios de desenvolvimento (Winnicott, 2006).

Este estudo não pretende abordar todos os aspectos da relação mãe-bebê com deficiência auditiva, mas se restringe à relação mãe-bebê durante o processo de diagnóstico, ou seja, desde o processo de identificação de uma alteração auditiva, do diagnóstico recebido em outra instituição até o diagnóstico final da deficiência auditiva do filho no HRAC-USP. Pretende-se investigar os depoimentos das 
mães nesse período em que estão em atendimento no Centro de Pesquisas Audiológicas do HRAC-USP, compreender o que se passa com elas e o que representa esse momento em sua vida. Este estudo pode trazer contribuições aos profissionais que atuam na área, especialmente nos programas de intervenção precoce e no apoio emocional aos pais.

\section{Metodologia}

Anteriormente à execução deste estudo, o projeto foi submetido ao Comitê de Ética e Pesquisa em Seres Humanos do HRAC-USP e aprovado conforme o documento Of. nº. 41/2010-SVAPEPE-CEP. Após a autorização, as mães foram contactadas conforme o agendamento da rotina de atendimento do Centro de Pesquisas Audiológicas do HRAC-USP e esclarecidas sobre o objetivo do estudo, com uma explicação detalhada do termo de consentimento livre e esclarecido.

Neste trabalho, foi utilizada a abordagem qualitativa, realizada por meio do método fenomenológico, que é um recurso apropriado para pesquisar a vivência e que possibilita mostrar, descrever e compreender a experiência do modo como é vivida por essas mães (Bruns \& Holanda, 2003; Martins \& Bicudo, 1989; Valle, 1997; Yamada \& Valle, 2013). O foco principal é a experiência vivida pelas mães, no processo de diagnóstico da deficiência auditiva do bebê, com vistas a procurar a estrutura essencial ou os elementos invariantes do fenômeno e o seu significado central. Para a fenomenologia, ao trabalhar com determinado fenômeno, considera-se que o objeto de estudo não existe em si, mas sempre em relação ao sujeito que o vivencia (Bruns \& Holanda, 2003).

A entrevista na abordagem fenomenológica busca uma linguagem que seja "a fala originária" (Carvalho, 1987), uma vez que a "fala" das mães em questão é via de acesso ao fenômeno interrogado. Como instrumento para alcançar a percepção das mães, foram utilizadas entrevistas individuais contendo a pergunta-guia: "Como é ser mãe de uma criança com deficiência auditiva?". Buscou-se uma compreensão da realidade subjetiva dessas mães, deixando-as falar à vontade, sem serem interrompidas.

As entrevistas foram realizadas após a conclusão do diagnóstico da deficiência auditiva, entre os meses de março e maio de 2009. Os depoimentos foram gravados, transcritos de forma literal, e os fenômenos foram elucidados e agrupados em categorias, seguindo as orientações de Martins e Bicudo (1989).

Participaram desta pesquisa sete mães de crianças na faixa etária de 8 meses a 1 ano e 6 meses de idade, sendo que seis desses bebês eram prematuros e considerados de alto risco, como mostra o quadro 1 . 


\section{Quadro 1 - Caracterização dos participantes}

\begin{tabular}{|c|c|c|c|c|c|c|c|}
\hline Participante & Criança $^{1}$ & $\begin{array}{c}\text { Idade } \\
\text { da } \\
\text { mãe }\end{array}$ & $\begin{array}{l}\text { Escolaridade } \\
\text { da mãe }\end{array}$ & $\begin{array}{l}\text { Idade da } \\
\text { criança }\end{array}$ & $\begin{array}{c}\text { Idade no } \\
\text { diagnóstico }\end{array}$ & $\begin{array}{l}\text { Intercorrências } \\
\text { neonatais }\end{array}$ & $\begin{array}{c}\text { Estado de } \\
\text { origem }\end{array}$ \\
\hline 1 & Antônio & $\begin{array}{l}32 \\
\text { anos }\end{array}$ & Ensino médio & 11 meses & 5 meses & $\begin{array}{l}\text { - Prematuridade } \\
\text { extrema; } \\
\text { - baixo peso; } \\
\text { - permanência em } \\
\text { UTI por } 3 \text { meses. }\end{array}$ & $\begin{array}{l}\text { Rio de } \\
\text { Janeiro }\end{array}$ \\
\hline 2 & Bruno & $\begin{array}{l}35 \\
\text { anos }\end{array}$ & Ensino médio & 11 meses & 7 meses & $\begin{array}{l}\text { - Mãe teve } \\
\text { citomegalovírus; } \\
\text { - prematuridade } \\
\text { extrema; } \\
\text { - baixo peso. } \\
\text { - parada } \\
\text { respiratória; } \\
\text { - permanência em } \\
\text { UTI por quatro } \\
\text { meses. }\end{array}$ & $\begin{array}{l}\text { Rio de } \\
\text { Janeiro }\end{array}$ \\
\hline 3 & Carlos & $\begin{array}{l}26 \\
\text { anos }\end{array}$ & $\begin{array}{l}\text { Ensino } \\
\text { fundamental }\end{array}$ & 12 meses & 7 meses & $\begin{array}{l}\text { - Prematuridade; } \\
\text { - anemia; } \\
\text { - transfusão } \\
\text { sanguínea; } \\
\text { - icterícia; } \\
\text { - permanência em } \\
\text { UTI por um mês. }\end{array}$ & $\begin{array}{l}\text { Espírito } \\
\text { Santo }\end{array}$ \\
\hline 4 & Daiane & $\begin{array}{l}21 \\
\text { anos }\end{array}$ & Ensino médio & 8 meses & 10 meses & $\begin{array}{l}\text { - Sem } \\
\text { intercorrências. }\end{array}$ & Paraná \\
\hline 5 & Eduarda & $\begin{array}{l}32 \\
\text { anos }\end{array}$ & $\begin{array}{l}\text { Ensino } \\
\text { superior }\end{array}$ & 16 meses & 14 meses & $\begin{array}{l}\text { - Prematuridade; } \\
\text { - anóxia. }\end{array}$ & $\begin{array}{l}\text { Minas } \\
\text { Gerais }\end{array}$ \\
\hline 6 & Fábio & $\begin{array}{l}35 \\
\text { anos }\end{array}$ & $\begin{array}{l}\text { Ensino } \\
\text { superior }\end{array}$ & 14 meses & 16 meses & $\begin{array}{l}\text { - Infecção } \\
\text { hospitalar; } \\
\text { - transfusão } \\
\text { sanguínea; } \\
\text { - permanência em } \\
\text { UTI por dois dias. }\end{array}$ & $\begin{array}{l}\text { Minas } \\
\text { Gerais }\end{array}$ \\
\hline 7 & Gabriel & $\begin{array}{l}43 \\
\text { anos }\end{array}$ & Ensino médio & 18 meses & 6 meses & $\begin{array}{l}\text { - Prematuridade; } \\
\text { - permanência em } \\
\text { UTI. }\end{array}$ & $\begin{array}{l}\text { Minas } \\
\text { Gerais }\end{array}$ \\
\hline
\end{tabular}

Fonte: dados da pesquisa.

\footnotetext{
* Todos os nomes citados são fictícios.
} 


\section{Resultados e discussão}

Os relatos das mães possibilitaram perceber as convergências de suas falas e agrupá-las em unidades de significação dos conteúdos. Tal agrupamento em categorias ou temas revela a essência de suas experiências, que emergiram em cinco unidades de significado:
a) suspeita e vivência de ameaça;
b) diagnóstico da deficiência auditiva;
c) sentimentos mais frequentes;
d) novas percepções da deficiência auditiva. Nessa perspectiva, as unidades de significado foram analisadas, como segue:

\section{1) Suspeita e vivência da ameaça}

Nesta categoria, serão apresentadas as falas referentes à suspeita de que algo ruim poderia acontecer e à ameaça, por serem mães de bebês prematuros e de alto risco, no período neonatal:

Ele nasceu prematuro, os médicos falaram que não sabiam como vai ser na parte cerebral. Então foi aquela expectativa que poderia vir algum 'probleminha' pela frente." (1)

"Ele nasceu prematuro e ficou internado [...] O neurologista falou que quando completar um ano é que dará para saber se terá alguma lesão... (2)

Ele nasceu prematuro e sobreviveu, e me avisaram que ele iria ficar com sequelas, mas não sabemos qual vai ser a sequela. (3)

Ele foi prematuro, pegou uma infecção e ficou internado. O pediatra já havia me advertido que talvez ele poderia ter alguma deficiência. (5)

Tinha resistência de levar no neurologista, o neurologista poderia falar: 'Tem mais uma deficiência' [...] Eu tinha essa preocupação, além da deficiência auditiva, tem mais outra coisa. Eu não sei o que fazer, como eu vou lidar com isso. (6)

Ele ficou na UTI, fez o teste da orelhinha, e os médicos pediram os exames. Fizeram vários exames e não tinham certeza de nada. (7)

O período neonatal é essencial para o estabelecimento do vínculo e desenvolvimento psíquico e emocional da criança (Iungano, 2009). O investimento na maternidade se torna ameaçado pela prematuridade e, no período perinatal, é estabelecida uma relação tumultuada pelo nascimento prematuro. A separação entre psique e corpo é, no prematuro, bastante abstrata, já que seu aparato em desenvolvimento não tem a complexidade que permite fazer tal distinção. O desenvolvimento psíquico depende de investimento afetivo, que se traduz como cuidado, maternagem ou amor parental. 
Nos relatos 1, 2, 3 e 5, as crianças nasceram prematuras e tiveram complicações durante e após o parto, sendo consideradas bebês de alto risco, e, nos relatos $6 \mathrm{e}$ 7 , embora os bebês não fossem prematuros, eram de alto risco. Nessas situações de nascimento, a possibilidade de sequelas futuras, algum tipo de deficiência e até mesmo dúvidas quanto à sobrevivência da criança era comum, o que gerou nas mães grande angústia e sentimentos ambivalentes.

A prematuridade é uma realidade descrita como um intervalo, pois ela deu à luz, mas não pode "atingir a completude da função materna". A hospitalização do bebê rompe uma interação de intensa afetividade. A imagem do bebê fica implicada pelas reaçôes intensas e ambivalentes que o bebê real provoca, e a própria mãe, identificada com o filho, pode se ver como insuficiente e geradora de um bebê falho. "O investimento afetivo, necessário para a construção psíquica, é prejudicado quando o objeto no qual a mãe deve investir remete à sua imperfeição" (Iungano, 2009, p. 29). Nesse sentido, Lima, Assis, Mercês e Griz (2008) apontam as dificuldades das mães de bebês nascidos pré-termos em definir seu papel materno de cuidador do filho. Essas dificuldades foram percebidas nos relatos das mães entrevistadas.

Para as mães deste estudo, as interações começaram a ser construídas no hospital, numa situação muito peculiar de fragilidade e estresse. Esse momento foi marcado, também, pela angústia negativa do futuro, contribuindo para que as mães se sentissem em constante ameaça. Elas relatam a forma como os profissionais da saúde informam sobre o problema e fazem colocaçôes que geram angústia e dúvida, retratando o despreparo dos profissionais. Quando os pais são informados, no momento do nascimento, que a criança tem algum tipo de problema ou deficiência, o nascimento passa a representar um momento de tristeza, desespero, confusão e medo. Grande parte da reação dos pais é determinada pelo tipo de informação fornecida, a forma como ela é apresentada e a atitude da pessoa que faz a comunicação (Lima et al., 2008; Yamada $\&$ Valle, 2013).

Fraga, Linhares, Carvalho \& Martinez (2008) apontam que, após o nascimento do bebê e durante sua internação na unidade de tratamento intensivo neonatal, as mães de bebês nascidos pré-termo apresentam ansiedade elevada que, em alguns casos, prolonga-se após a alta hospitalar. Os autores constatam que quanto maior a ansiedade das mães, pior o desenvolvimento de seus filhos. A ansiedade materna é, entre outras, uma variável significativa do ambiente familiar que afeta o desenvolvimento da criança em diversas áreas. É nesse momento de fragilidade que o acolhimento e escuta devem se fazer presentes, estabelecendo um vínculo de confiança entre o profissional e, neste caso, as mães. 


\section{2) O diagnóstico da deficiência auditiva}

O impacto do diagnóstico de deficiência auditiva é sentido como um dos momentos mais tristes vividos por essas mães, que experienciam a perda dos sonhos, o choque e a angústia diante da notícia.

Eu fiquei muito triste! Mas como, meu filho não vai me escutar? Não vai ouvir minha voz? (1) $O$ médico fez o teste da orelhinha e contou que o menino não estava escutando, ia ficar surdo! Ai foi um choque! Nenhuma mãe espera ter um filho com problema. (2)

A gente desconfia e não quer saber... Sabia que ia dar algum 'probleminha' no exame, mas você espera que não dê... Você não quer aceitar. (4)

O resultado chegou pelo correio! Já fui lendo e foi me dando uma dor no coração... Chorei até! (5)

O médico falou que ele tinha deficiência profunda depois de vários exames [...] Não foi fácil receber uma noticia assim, você espera ter um filho normal, com saúde. (7)

Vários são os estudos que descrevem o impacto do diagnóstico da deficiência auditiva nos pais e os sentimentos vivenciados por eles nesse período (Boscolo \& Santos, 2005; Kurtzer-White \& Luterman, 2003; Luterman \& Ross, 1991; Ribeiro, Yamada \& Silva, 2005; Silva, Zanoli \& Pereira, 2008; Yamada \& Valle, 2013). A especificidade deste trabalho é que o diagnóstico ocorre precocemente na vida da criança, em um momento vulnerável, em que a mãe está se recuperando do nascimento de seu filho e ambos, pai e mãe, estão reorganizando suas identificações e papéis na relação familiar.

No relato 5, a mãe recebeu o diagnóstico pelo correio, ficando evidente o despreparo dos profissionais de saúde, deixando-a sem suporte em um momento que precisava de apoio e informações. Após o diagnóstico, muitas vezes, os pais precisam tomar decisóes diante do novo problema, do desconhecido e da falta de orientaçôes sobre suas dúvidas (Vitti, 2006). Diante disso, concluímos que o profissional tem o dever de auxiliar a família a superar esse período tão conturbado.

Kurtzer-White e Luterman (2003) observam os efeitos negativos do diagnóstico precoce nas mães. Conforme mudamos de um modelo de diagnóstico iniciado pelos pais para um modelo iniciado por uma instituição, o enfrentamento se inicia sem qualquer preparação e sem qualquer tempo para os pais lidarem com a criança. Vitti (2006) complementa que o estabelecimento do vínculo mãebebê acaba sendo afetado pela ansiedade, pois tem início uma bateria de testes auditivos para a confirmação ou não da suspeita.

O abalo que a mãe vivencia com a notícia do diagnóstico é decisivo para o futuro do sujeito que está por vir e na maneira como ele irá se constituir. O bebê se identifica com aquilo que o adulto lhe transmite e lhe dedica. No relato das 
mães entrevistadas, foram observados tristeza, estado de choque e dificuldade de aceitação da deficiência auditiva do filho (Solé, 2006).

Conforme destaca Yamada (2006), com os programas de detecção precoce da deficiência auditiva na infância e a atuação de profissionais na maternidade, o diagnóstico da surdez tem sido cada vez mais precoce, o que é fundamental para o desenvolvimento da linguagem na criança, possibilitando uma intervenção para que a criança possa atingir níveis de linguagem próximos aos da criança ouvinte. No entanto, são atendidos bebês cujos pais nem sequer suspeitavam da perda auditiva, e esse momento passa a ser de choque e ruptura dos sonhos que os pais depositavam na criança idealizada.

Os esforços para o tratamento precoce têm deixado os pais sem suporte emocional no diagnóstico, provocando uma lacuna que deve ser fechada. A falta de suporte emocional da equipe profissional tende a deixar as mães inseguras e sozinhas com seus sentimentos confusos. Esses sentimentos negativos alteram a relação com seu bebê, nos estágios iniciais da vida da criança (Kurtzer-White \& Luterman, 2003).

\section{3) Sentimentos mais frequentes}

O diagnóstico da deficiência auditiva é permeado por sentimentos predominantemente negativos, como está descrito a seguir:

\section{1) Choque}

Foi um choque. Nenhuma mãe espera ter um filho que naş̧a com problemas. (1) Isso me chocou. No momento eu não tive reação nenhuma. [...] Porque eu fiquei sabendo que ele não era uma criança normal. (2)

Eu fiquei chocada, não esperava. Você vê acontecer com outras pessoas e nem imagina que vai acontecer com você. (4)

"Tive um choque em saber... Uma coisa que a gente não espera." (5)

"Eu me senti sem chão. Como eu vou trabalhar com uma criança deficiente? Correr atrás de um tratamento? Deixar de tudo pra ficar só com ele [...]” (7)

As mães ficam em choque e não querem acreditar. É um momento difícil em que são perdidas suas últimas esperanças de ter um filho "normal". As mães relatam o impacto, a não aceitação e a desorientação. Após receber o diagnóstico, a reação imediata dos pais da criança surda é de choque, caracterizado por um divórcio de si mesmo, perante a situação de crise. O mundo se torna ameaçador para os pais, e a reação física insegura reduz sua concentração nas necessidades da criança, o que tende a provocar um afastamento do seu bebê (Silva, Zanolli 
\& Pereira, 2008).

Winnicott (2006) observa que os cuidados maternais permitem à criança viver e se desenvolver desde a concepção. Se esses cuidados forem insatisfatórios, física e emocionalmente, a criança não é capaz de adquirir sua independência. Quando a mãe está em estado de choque, não dispensa a atenção necessária que o seu bebê precisa, não sendo suficientemente boa.

\section{2) Sentimento de tristeza}

Foi muito dolorido ter um filho com deficiência auditiva! (2)

Eu chorei, fiquei muito triste... Meu filho não é normal, vai ser surdo eternamente, eternamente não vai ouvir ninguém chamar, ninguém falar. (3)

Eu fiquei muito triste! [...] Teve um sábado que eu não tive nem coragem de levantar da cama, de tão deprimida que eu estava, só pensando nisso. (5)

Você se sente triste. Eu parei com tudo [...]. Minha rotina mudou bastante, bate uma canseira em mim que eu não quero nem limpar a casa. [...] Aquela vontade que eu tinha que lutar pra viver não tenho mais. (7)

Os relatos das mães são marcados pelo sentimento de tristeza, quando ficam sabendo que seu filho tem deficiência auditiva. Esse estado emocional tende a persistir durante a fase de aceitação da deficiência da criança. A tristeza está relacionada pelo luto do filho perfeito, o que pode ser observado na mãe 3, quando verbaliza que seu filho não é normal. Existe a crença de que o filho com deficiência auditiva será surdo eternamente, caracterizando uma vivência de desesperança.

A relação mãe-bebê vai se construindo desde o período pré-natal e é influenciada pelas expectativas que a mãe tem sobre o seu bebê. Quando a criança perfeita que a mãe esperava não vem, terá de aceitar, em seu lugar, algo muito aquém de suas expectativas (Piccinini, Gomes, Nardi \& Lopes, 2008). Essa tomada de consciência traz consigo uma dor profunda e grande decepção para a mãe 7 , que vive um conflito emocional e existencial, sentindo-se abandonada e sem forças para continuar a sua rotina e a viver. Mostra-se vulnerável diante da situação, não conseguindo apreender a facticidade de ter um filho com deficiência auditiva.

Os relatos 5 e 7 sugerem um estado depressivo das mães entrevistadas, em que o impacto do diagnóstico interfere também no seu cotidiano e persiste durante um período maior. A ansiedade e a depressão materna podem persistir e serem fatores de risco para o desenvolvimento de psicopatologias no filho (Correia $\&$ Linhares, 2007).

Winnicott (2006) acredita que uma mãe depressiva não é capaz de oferecer 
o desenvolvimento libidinal e o amor objetal que permitem que a criança estabeleça uma relação saudável com sua mãe, de tal forma que conflitos vivenciados em relação à figura materna são expressos por meio de transtornos alimentares, visto ser a amamentação a principal experiência nessa fase da vida. No momento da amamentação, espera-se que a mãe esteja disponível e dê a devida atenção ao seu bebê, para uma maternagem suficiente, com o suprimento de determinadas necessidades, para que, mais tarde, não apareçam bloqueios nas fases do desenvolvimento infantil.

Existe grande relação entre a resolução da tristeza, a interação mãe-filho, o vínculo parental, a disponibilidade emocional da mãe e o desenvolvimento do "self" da criança com a deficiência auditiva. A sensibilidade maternal, caracterizada pelo calor/amor e conectividade emocional, em relação à criança, traz ganhos expressivos à linguagem. Quanto mais emocionalmente conectada à mãe for a criança, maior será o seu ganho na linguagem (Kurtzer-White \& Luterman, 2003).

\section{3) Sentimento de culpa}

Eu me senti culpada por não notar que estava grávida, não sentia a mudança no meu corpo. Será que algum momento eu rejeitei o meu filho? (1)

A gente sempre pensa: mas por que meu filho é deficiente auditivo? [...] Uma angústia de ter feito algo errado! Talvez eu tenha feito alguma coisa. (2)

Será que é por que eu falei que ia tirar e Deus me castigou? Então eu tenho que pagar por isso? (3) Você procura buscar uma resposta! Eu cometi uma coisa errada. [...] Aquelas tintas todas que passei no cabelo durante a gravidez... Alguma coisa interferiu. (6)

Como se pode verificar nos relatos acima, o sentimento de culpa nessas mães geralmente está relacionado à angústia de acreditarem terem feito "algo errado", buscando algum tipo de explicação quanto ao motivo do que aconteceu. As afirmações de Kurtzer-White e Luterman (2003) vêm confirmar que o sentimento de culpa das mães de crianças com deficiência auditiva está relacionado à causa da deficiência auditiva.

$\mathrm{Na}$ vivência dos sujeitos 1 e 3, os relatos demonstram a crença de que a deficiência auditiva do filho pode ter acontecido pela rejeição da criança na gravidez. A mãe 6 se culpa por ter passado tinta no cabelo no período em que estava grávida. As mães acreditam que cometeram erros na gravidez e a deficiência da criança aconteceu como castigo.

Muitos pais sentem a preocupação de terem sido os causadores do problema. São frequentes os sentimentos de autorrecriminação, remorso e fantasias de que a 
falta de amor, cuidados e desejo pelo bebê provocam acontecimentos dramáticos, e os pais sentem que estão sendo punidos por alguma falta grave que cometeram e, por isso, o "castigo" (Silva, Zanoli \& Pereira, 2008).

Esse é um período de questionamentos e sentimentos de culpa. Algumas mães sentem-se pessoalmente responsáveis pelas condiçôes em que seu filho veio ao mundo (Buscaglia, 1997). Pensamentos e emoções produzem fortes sentimentos de autocensura que afetam a criança. "Sentindo-se culpada e impotente, a mãe pode se ver incapaz de investimentos no filho, o que afeta os primeiros contatos com a criança”" (Iungano, 2009, p. 29).

Desde as primeiras horas de vida, o bebê estabelece comunicação. O desenvolvimento do bebê, por meio da comunicação sensorial (auditiva, visual, olfativa, gustativa e tátil), é favorecido pela forma com que a mãe o estimula, carrega, segura e escuta, quando ele expressa suas necessidades, suas mensagens. A comunicação se estabelece na origem, pela linguagem corporal, enquanto a função psíquica se apoia e se desenvolve na vivência corporal (Navarro, 1995).

Considerando a singularidade das relações entre mãe e filho e as transformações e conflitos vivenciados na fase perinatal, é possível que a mãe, também prematura e se sentindo culpada, não esteja preparada e não consiga estabelecer um a vivência de comunicação satisfatória com o filho (Iungano, 2009).

\section{4) Negação, raiva, rejeição}

É como se ele não fosse deficiente auditivo! Tem horas que eu nem noto. Em momento algum eu pensei: não vou cantar porque ele não tá me ouvindo [...] (1)

Eu tratava como se ele não fosse meu filho [...]. Não queria nem pegar ele no colo, acho que rejeitei um pouco [...]. Ele mal me via, já chorava, tinha medo de mim [...]. Agora não estou mais com aquela raiva. Eu tenho que aceitar isso... Agora tenho que aceitar. (2)

É uma coisa que a gente não espera, a gente desconfia, mas não quer saber. Você não quer aceitar. É muito dificil [...]. (4)

Num primeiro momento, a gente sente tudo. Sente raiva, rejeição, dó, quer redobrar o amor, é tanta confusão! [...] Aquele tumulto na cabeça que você não consegue identificar nada. (6)

Após o diagnóstico da deficiência auditiva, os sentimentos negativos persistem e são vivenciados pelas mães como negação, raiva e rejeição pela criança.

No relato 1, a mãe trata a criança como se não tivesse deficiência, numa atitude de minimizar o problema, e expressa que, muitas vezes, não nota que seu filho tem perda auditiva. Os pais reorganizam as expectativas para fazer a nova realidade tolerável. Vivem na bolha da negação, tornando a surdez normal, e essa negação permanece até que a mãe alcance a nova realidade (Kurtzer-White 
\& Luterman, 2003). Nos relatos 2 e 4, as mães apresentam dificuldade em aceitar o diagnóstico, relatam a vivência da negação, mesmo quando recebem o diagnóstico e não querem acreditar.

Silva et al. (2008), ao se referirem especificamente à surdez, afirmam que, em um primeiro momento, as mães apresentam uma reação inicial de descrença. Pode aparecer o mecanismo psicológico da negação, quando a mãe ignora a observação da criança que falha ao responder à sua voz, ou da racionalização, na qual os pais creem em alternativas fictícias que substituam a dor realista e buscam explicaçôes para fatos observados, como "a criança ouve o que quer ouvir".

O sentimento de raiva aflora e se manifesta por meio do desapreço e da rejeição pelo filho. Nos relatos 2 e 6 , a negação é acompanhada pela raiva e rejeição pelo filho. A mãe 2 expressou muita dificuldade na interação com o seu filho, ao afirmar que o tratava como se não fosse seu filho, rejeitando-o. O filho reagia aos estímulos da mãe com medo e choro. As mães lutam com seus próprios sentimentos, opostos e contraditórios, sentindo inicialmente uma aversão física e emocional muito forte pela criança, condição que impossibilita envolverem-se em carinhos e cuidados, não conseguindo estabelecer o vínculo materno e o apego ao bebê.

A mãe 6 relata sentimentos estranhos e confusos em relação a si mesma e ao filho e confunde-se diante de tantos sentimentos ambíguos. Quando ocorre uma ruptura dessa natureza, a mãe não contribui para a formação de um ego saudável do filho. Nesse caso, forma-se um ego fragilizado, que tem como consequência o surgimento de patologias psicóticas e neuróticas. É na experiência corporal com a mãe que o holding se inicia, pois um dos primeiros objetivos é o segurar físico do bebê, que é, ao mesmo tempo, uma experiência física e uma vivência simbólica, que representa firmeza com que é amado e desejado (Winnicott, 2006).

De acordo com Navarro (1995), os movimentos expressivos do bebê, que traduzem conforto/desconforto, demanda/satisfação, prazer/desprazer, vão se moldar, criando um código corporal conforme as reaçōes corporais positivas ou negativas do meio maternal. A mãe, abalada por sentimentos de raiva, rejeição e negação, não preenche essas funções de forma satisfatória, e o bebê não se sente compreendido e atendido nas suas demandas, podendo então construir um envelope de mal-estar, narcisicamente investido. 


\section{5) Nova percepção da deficiência auditiva}

Eu sofri muito antes de vir aqui [...]. E depois que eu vi que tem recursos, ficou mais leve! Vejo que tem crianças falando! Agora estou mais envolvida. (1)

Quando eu cheguei aqui, vi várias crianças com o mesmo problema. Estou levando. (3)

A gente fica sabendo do tratamento, fiquei mais tranquila... Fiquei sabendo que ela pode ouvir [...]. A gente aprende muito! (4)

A gente troca informação e experiência. Você vê casos tão mais complicados que o seu [...]. Isso acaba confortando! (6)

Os relatos revelam que, após as mães frequentarem o CPA, ocorre uma mudança na percepção da deficiência auditiva, seus sentimentos angustiantes se amenizam e as possibilidades ampliam. A convivência na sala de espera possibilita fazer amizades com outras mães, trocar experiências, reconhecer sentimentos e vivências semelhantes, promovendo a coesão grupal espontânea, alianças fraternais e o desencadeamento de ações transformadoras (Ribeiro, Yamada \& Tavano, 2007).

Ao entrar em contato com outras crianças, as mães percebem novas possibilidades, que até então desconheciam e ficam mais abertas para observar os resultados do tratamento em crianças maiores. Todas as mães relatam o seu sofrimento e como se sentem mais leves e tranquilas durante o processo de atendimento no CPA. É um momento importante, quando surge uma nova expectativa e a perspectiva de uma "luz no fim do túnel". As mães têm a oportunidade de ressignificar a deficiência auditiva e, consequentemente, melhorar a relação com seu filho, o que vem a corroborar o estudo de Ribeiro et al. (2007) sobre a vivência de mães de crianças com deficiência auditiva, em sala de espera, revelando a formação de grupos naturais e caracterizando situações de ajuda mútua entre as mães, como empatia pelo problema do outro, construção de um significado mais positivo ante a deficiência auditiva, visualização de novos horizontes no desenvolvimento do filho, diluição do próprio preconceito, apoio, encorajamento e incentivo para a participação na reabilitação.

No entanto, para alguns pais, a busca da criança "normal" que supunham ter nunca terminará se não aprenderem a aceitar a criança como ela é. Tanto a criança como os pais poderão nunca integrar a surdez às suas vidas e não conseguirão superar isso (Kurtzer-White \& Luterman, 2003). 


\section{Conclusão}

O estudo mostra que o fenômeno referido, ou seja, a experiência vivida pelas mães, diante do processo de diagnóstico de deficiência auditiva do bebê, representa um dos momentos mais tristes em sua trajetória de vida. Inicialmente, a ameaça no período neonatal parece romper a interação de afetividade com o bebê e configurar-se uma relação angustiante e de sentimentos ambivalentes. Com o diagnóstico da deficiência auditiva de seu filho, experienciam a perda dos sonhos, o choque e a angústia. $O$ desamparo enfrentado pelas mães pode ser amenizado se forem utilizadas maneiras mais adequadas de informar o diagnóstico. A ausência dessas condições aumenta as dificuldades no enfrentamento da nova situação.

Considerando que a presença e persistência dos sentimentos negativos nas mães constituem potencial fator de risco, tanto para o equilíbrio emocional materno quanto para o desenvolvimento integral da criança, compreender a mãe no processo de diagnóstico do problema de seu filho é de extrema importância para os profissionais, para que elas possam ver a deficiência auditiva na dimensão vivencial, com suas limitações e fragilidades.

Assim, poder proporcionar às mães meios de prevenção para os traumas provenientes do "momento da notícia", no diagnóstico precoce, após o nascimento da criança, bem como identificar os fatores que se encontram relacionados ao potencial efeito negativo no desenvolvimento infantil podem ainda ajudar a mãe a superar a dor do diagnóstico e estabelecer uma relação saudável com o seu filho. Nessa situação, as mães necessitam de ajuda, informação, apoio, orientação e compreensão, para que possam ajustar-se como pessoas e desempenhar satisfatoriamente o seu papel materno.

A abordagem e o referencial que buscam compreender o que se passa com as mães das crianças com deficiência auditiva, no processo de diagnóstico, são fundamentais para os profissionais privilegiarem uma prática centrada em novas modalidades de relação, a fim de que se alcance efetivamente uma assistência humanizada integral à mãe e à criança. $\mathrm{O}$ trabalho sistematizado, realizado por uma equipe interdisciplinar, durante e após o diagnóstico da deficiência auditiva, é de fundamental importância para o equilíbrio emocional dos pais e afetará na relação com o seu filho e, consequentemente, no desenvolvimento integral da criança. 


\section{Referências}

Beltrami, L., Souza, A. P. R. \& Dias \& L. O. (2013). Ansiedade e depressão em mães de crianças com distúrbios de linguagem: a importância do trabalho interdisciplinar. Fractal: Revista de Psicologia, 25(3), 515-530.

Boscolo, C. C. \& Santos, T. M. M. (2005). A deficiência auditiva e a família: sentimentos e expectativas de um grupo de pais de crianças com deficiência da audição. Distúrbios da Comunicação, 17(1), 69-75.

Bruns, M. A. T. \& Holanda, A. F. (2003). Psicologia e fenomenologia: reflexóes e perspectivas. Campinas: Alínea.

Buscaglia, L. (1997). Os deficientes e seus pais: um desafio ao aconselhamento. (3a ed.). Rio de Janeiro: Record.

Carvalho, A. S. (1987). Metodologia da entrevista: uma abordagem fenomenológica. Rio de Janeiro: Agir.

Correia, L. \& Linhares, M. B. M. (2007). Ansiedade materna nos períodos pré e pós-natal: revisão da literatura. Revista Latino-Americana de Enfermagem, 15(4), 677-683.

Costa A. O., Bevilacqua M. C. \& Nascimento, L. T. (2006). Implantes cocleares em crianças. In L. Lavinsky, Tratamento em Otologia. (pp. 478-484). Rio de Janeiro: Revinter.

Fraga, D. A., Linhares, M. B. M., Carvalho, A. E. V. \& Martinez, F. E. (2008). Desenvolvimento de bebês nascidos pré-termo e indicadores emocionais maternos. Psicologia: Reflexão e crítica, 21(1), 33-41.

Guimarães, R. F. (2005). Da triagem auditiva neonatal ao diagnóstico: os pais diante da suspeita de deficiência auditiva no filho. (Dissertação de Mestrado). Pontifícia Universidade Católica de São Paulo, Programa de Pós-Graduação em Fonoaudiologia, São Paulo.

Iungano, E. M. (2009). A relação entre a mãe e o bebê prematuro internado em UTI neonatal. Pediatria moderna, 45(1), 26-30.

Kurtzer-White, E. \& Luterman, D. (2003). Families and children with hearing loss: grief and coping. Mental Retardation and Developmental Disabilities Research Reviews, 9(4), 232-235.

Lima, M. L. L. T., Assis, A. B. R, Mercês, G. B. \& Griz, M. (2008). Triagem auditiva: perfil socioeconômico de mãe. Revista CEFAC, 10(2), 254-260.

Luterman, D. \& Ross, M. (1991). When your child is deaf: a guide for parents. Parkton: York Press. 
Mahl, F. D., Mattiazzi, A. L., Angst, O. V. M., Kessler, T. M. \& Biaggio (2013). Estudo do perfil sociodemográfico e psicossocial de mães de neonatos e seus conhecimentos sobre a triagem auditiva neonatal. O mundo da saúde, 37(1), $35-43$.

Martins, J. \& Bicudo, M. A. V. (1989). A pesquisa qualitativa em psicologia: fundamentos e recursos básicos. São Paulo: Moraes.

Moret, A. L. M. (2005). Princípios básicos da habilitação da criança deficiente auditiva com implante coclear. In M. C. Bevilacqua \& A. L. M. Moret, Deficiência auditiva: conversando com familiares e profissionais de saúde. (pp. 225-234). São José dos Campos: Pulso.

Navarro, F. (1995). Caracteriologia pós-reichiana. São Paulo: Summus.

Piccinini, C. A., Gomes, A. G., Nardi, T. \& Lopes, R. S. (2008). Gestação e a constituição da maternidade. Psicologia em Estudo, 13(1), 63-72.

Pontes, A. C. L. R. (2005). Fundamentos de aquisição e desenvolvimento da linguagem. In M. C. Bevilacqua \& A. L. M. Moret, Deficiência auditiva: conversando com familiares e profissionais de saúde. (pp. 139-160). São José dos Campos: Pulso.

Redondo, M. C. F. \& Carvalho, J. M. (2000). O bebê surdo: tornando-se independente. Cadernos da TV escola, 1, 17-24.

Ribeiro, S. F. R., Yamada, M. O. \& Silva, C. (2005). Grupo de acompanhantes de pacientes com implante coclear: uma ação interdisciplinar da psicologia e do serviço social. Revista da SPAGESP, 6(1), 48-56.

Ribeiro, S. F. R., Yamada, M. O. \& Tavano, L. D. (2007). Vivência de mães de crianças com deficiência auditiva em sala de espera. Psicologia em Revista, 13, 91-106.

Silva, A. B. P., Zanolli, M. L. \& Pereira, M. C. C. (2008). Surdez: relato de mães frente ao diagnóstico. Estudos de Psicologia (Natal), 13(2), 175-183.

Silva, L. S. G. \& Gonçalves, C. G. O. (2013). Processo diagnóstico da surdez em crianças na percepção de familiares e gestores. Audiology Communication Research, 18(4), 293-302.

Solé, M. C. P. (2006). A linguagem e a construção do vínculo mãe-bebê. In Anais, 5 Congresso Surdez: Família, Linguagem, Educação (pp. 259-264). Rio de Janeiro: INES, Divisão de Estudos e Pesquisa.

Stuart, A., Moretz, M. \& Yang, E. Y. (2000). An investigation of maternal stress after neonatal hearing screening. American Journal of Audiology, 9(2), 135-141. 
Valle, E. R. M. (1997). Câncer infantil: compreender e agir. Campinas: Psy.

Vitti, S. V. (2006). Intervenção fonoaudiológica junto à família durante um programa de triagem auditiva neonatal universal.(Dissertação de Mestrado). Universidade de São Paulo, Faculdade de Odontologia de Bauru, Bauru.

Winnicott, D. W. (2006). O bebê e suas mães. São Paulo: WMF.

Yamada, M. O. (2006). A linguagem e a construção do vínculo mãe-bebê. In Anais, 5 Congresso Internacional Surdez: Família, Linguagem, Educação, (pp. 265271). Rio de Janeiro: INES, Divisão de Estudos e Pesquisa.

Yamada, M. O. \& Valle, E. R. M. (2013). Vivência de mães na trajetória de seus filhos com implante coclear: fatores afetivos e emocionais. São José dos Campos: Della Bídia.

Yoshinaga-Itano, C. \& DeUzcategui, A. (2001). Early identification and socialemotional factors of children with hearing loss and children screed for hearing loss. In E. Kutzer-White \& D. Luterman (Eds.), Early childhood deafness. (pp. 13-28). Baltimore: York Press. 